\title{
Metamalzeme Tabanlı İki Bantlı Mükemmel Soğurucu
}

\author{
Rafettin Aytekin ${ }^{1}$, Habibe Durmaz ${ }^{2 *}$ \\ ${ }^{1}$ Karamanoğlu Mehmetbey Üniversitesi, Mühendislik Fakültesi, Elektrik-Elektronik Mühendisliği Bölümü, Karaman, Türkiye (ORCID: 0000-0002-6986-059X), \\ mhndsrafet@gmail.com \\ 2*Karamanoğlu Mehmetbey Üniversitesi, Mühendislik Fakültesi, Elektrik-Elektronik Mühendisliği Bölümü, Karaman, Türkiye (ORCID: 0000-0002-5929-861X), \\ hdurmaz@kmu.edu.tr
}

(İlk Geliş Tarihi 13 Mart 2021 ve Kabul Tarihi 30 Mayıs 2021)

(DOI:10.31590/ejosat.891996)

ATIF/REFERENCE: Aytekin, R. \& Durmaz, H. (2021). Metamalzeme Tabanlı İki Bantlı Mükemmel Soğurucu. Avrupa Bilim ve Teknoloji Dergisi, (25), 28-33.

\begin{abstract}
$\ddot{\mathbf{O z}}$
Son zamanlarda mükemmel soğurucular (MS), karmaşık elektriksel ve manyetik geçirgenlik özelliklerinden dolayı büyük ilgi görmüştür. Malzemenin ve geometrinin doğru oranlarda seçilmesiyle MS' nin empedansı boş uzaya eşleştirilebilir; böylece geniş elektromanyetik spektrumda güçlü soğurum elde edilebilir. Özellikle metal-dielektrik bazlı plazmonik metamalzemelerden oluşan nanoyapılar, güçlü yakın alan geliştirme, negatif kırılma indeksi ve optik gizleme gibi benzersiz optik özellikler sergiler. Bu çalışmada, metamalzeme tabanlı farklı rezonanslarda aynı anda \%100' e yakın bir soğurumla çalışan iki bantlı U şeklinde antenlerden oluşan bir MS platformu önerilmiştir. MS platformunun ince ayar mekanizması için sonlu fark zaman alanı (FDTD) simülasyonları aracılığıyla spektral yanıtının geometrik parametrelere bağımlılığı sayısal olarak analiz edilmiştir. Soğurum tepkisini ve yakın alan dağılımlarının fiziksel temelleride sayısal olarak incelenmiştir. Sayısal hesaplamalarımız, ikili rezonanslarda U plazmonik anten sisteminin geniş ve kolayca erişilebilen yerel elektromanyetik alanları desteklediğini göstermektedir. Deneysel sonuçlar, teorik hesaplamalar ile oldukça uyumlu olduğu gösterilmiştir. Çift rezonanslı U şekilli antenler sahip oldukları güçlü ve erişilebilir elektromanyetik alandan dolayı güçlü yakın alan özelliklerine sahiptir ve çok sayıda spektral özellik gerektiren birçok uygulama için oldukça avantajlı olabilir. Ayrıca, önerilen U şekilli plazmonik antenlerin rezonans frekansı spektral olarak ayarlanabildiği için aktif filtreler, optik modülatörler, ultra hızlı anahtarlama cihazları, haberleşme, detektör ve biyoalgılama gibi çok çeşitli uygulamalar için de kullanılabilir.
\end{abstract}

Anahtar Kelimeler: Nanoyapı Üretimi, Metamalzemeler, Yüzey Plazmonları, Mükemmel Soğurucu

\section{Dual Band Perfect Absorber Based on Metamaterials}

\begin{abstract}
Recently, perfect absorbers (PAs) have attracted great attention due to their complex electrical permittivity and magnetic permeability properties. By choosing the right ratio of the material and geometry the impedance of the perfect absorber can be matched to to the free space; therefore, strong absorption in a wide range of electromagnetic spectrum. Especially, metal-dielectric based plasmonic metamaterials in nanometer scale exhibit unique optical properties such as strong near field enhancement, negative refractive index and optical cloaking. In this study, we propose a dual-band metamaterial base PA platform consisting of U-shaped antennas with unity absorption. The finite difference time domain (FDTD) method was used to numerically analyze the spectral response dependence on geometric parameters to fine tune the mechanism of the PA platform. The physical basis of the absorption response and near-field distributions of these nanoscale antennas were also studied numerically. Our numerical calculations show that U-shaped plasmonic antenna system supports large and easily accessible local electromagnetic fields. Experimental and theoretical results are found to be in good aggrement. U-shaped antennas with dual resonances with strong electromagnetic fields can be highly advantageous for a wide variety of applications that require a large number of spectral features with strong near field properties. In addition, since the resonance frequency of the proposed U-shaped plasmonic antennas can be adjusted spectrally, they can also be used for a wide variety of applications such as active filters, optical modulators, ultra-fast switching devices, communication, detectors and biosensing.
\end{abstract}

Keywords: Nanostructure Fabrication, Metamaterials, Surface Plasmons, Perfect Absorber

*Sorumlu Yazar: hdurmaz@kmu.edu.tr 


\section{Giriş}

Mükemmel soğurucular (MS), metamalzemelerin sahip olduğu negatif kırılma indisinden dolayı kolayca oluşturulabilirler (C. M. Soukoulis, 2007). Metamalzemelerin empedansı $(\mathrm{z}=\sqrt{\mu / \varepsilon}=1)$ çevresini saran uzaya kolayca ayarlanabildiği için maksimum güç transferi elde edilmesini ve 1şığın mükemmele yakın bir şekilde hapsedilmesini sağlar. $\mathrm{Bu}$ olağandişı elektromanyetik özellikleri nedeniyle metamalzemeler, mükemmel mercekleme (Grisha Spektor, 2015), biyo-algilama (Cameron Gilroy, 2019), optik enerji toplama cihazları (Seon-Young Rhim, 2020), yüzeyi güçlendirilmiş titreşim spektroskopisi (Arif E. Cetin, 2016) ve görünmezlik gizlemesi (Yakov Galutin, 2017) için son birkaç yılda büyük ilgi görmüştür. Landy ve arkadaşları bir elektrik rezonatörü ve kesik telden oluşan ve bağımsız olarak elektrik ve manyetik alanları destekleyen mikrodalga frekans aralığında çalışan ilk MS' yi göstermişlerdir (N. I. Landy, 2008). Metamalzemeler kullanılarak orta kızı̈ötesi bölgesine kadar dalgaboyu ayarlanabilen çoklu rezonanslı mühendislik metamalzemeleri (Arif E. Cetin, 2016), aktif filtreler (Luc Duempelmann, 2016), optik modülatörler (Bowen Li, 2017) ve biyo-sensörler (Alexander Belushkin, 2018) geliştirilmiştir. Tek, çift ve çok bantlı mükemmel soğurucu yapılar literatürde gösterilmiş ve farklı tasarımlarda üretimler gerçekleştirilmiştir (Ting Xie, 2017) (Arif E. Cetin, 2016) (Wang Xin, 2017) (Deepak Sood, 2017) (A. Degiron, 2004). Son yillarda birçok araştırmacı alt dalga boyutlarındaki anten tasarımlarını kullanarak optik (Tsai, 2006), kızılötesi (Biagioni, 2019), terahertz (THz) (Khwanchai Tantiwanichapan, 2017) ve mikrodalga (Rana Sadaf Anwar, 2018) frekans aralıklarında yüksek geçirgenliğe sahip yapılara odaklanmışlardır. Nanoantenlerin optik özellikleri çevresindeki ortamın kırılma indisine, antenlerin geometrik şekline ve yönüne, metal film kalınlığına ve kafes geometrisine bağlıdır (Ahmet Ali Yanik, 2008) (Yasa Ekşioğlu, 2018).

Geleneksel malzemelerin elektromanyetik özellikleri atomik ya da moleküler yapıya bağlıyken metamalzemelerin özelliği resonans elementinden kaynaklanmaktadır (N. I. Landy, 2008). Metamalzeme tabanlı MS' ler tipik olarak, alt metal film ile rezonatör görevi gören desenli üst metal plazmonik nanoanten ve bunlar arasına sıkıştırılmış dielektrik ara katmandan oluşan üç işlevsel katman kullanılarak tasarlanabilir (N. I. Landy, 2008). Üç katmanlı konfigürasyonda, dilektrik katmanın kalınlığı absorpsiyon seviyesini \% 100 ve rezonans düşüşün genişliğini (kalite faktörü, $\mathrm{Q}=\lambda / \Delta \lambda$ ) minimize etmeyi sağlayan önemli bir parametredir. MS' lerin en üst katmanında bulunan dalga boyundan daha küçük boyutlara sahip olan plazmonik anten bileşenleri, çalışma frekansından gelen radyasyonun çoğunu soğurur. En alt katmanı oluşturan kalın metal tabaka ise geçirgenliği önemli ölçüde azaltan optik ayna görevini üstlenir. Işığın antenlerle çiftlenmesi elektrik alan indüklerken, antenler ve taban metal levha arasındaki yakın alan etkileşmeleri alt katmanda ayna görüntüsü yüklerinin oluşmasına neden olur. $\mathrm{Bu}$ yükler ise manyetik alan indükleyen bir akım döngüsü oluşturur (Zhi Hao Jiang, 2011). Elektrik ve manyetik alanların genliği ve rezonans frekansının ayarlanması ile MS' nin empedansını boş uzaya eşleştirilebilir, bu da yansımayı en aza indirir. Yansıma en aza indirgenirken alttaki metal levha ile geçirgenliğin minimize edilmesi mükemmel soğurumun oluşmasını sağlar.
MS' nin etkin dalga boyu $\lambda_{\text {eff }}=2 n_{\text {eff }} \mathrm{L}+\mathrm{C}$ ile verilmektedir. Burada $\mathrm{n}_{\text {eff }}$ etkin kırılma indisi, $\mathrm{L}$ yalıtkan üzerindeki anten boyutu ve $\mathrm{C}$ sabit olarak verilmiştir. L uzunluğundaki bir nanorod anten için birinci dereceden dipolar plazmonik uyarımların rezonans dalga boyu yaklaşık olarak $\lambda_{\text {res }}=2 \mathrm{Ln}_{\text {eff }}+\mathrm{C}^{\prime}$ de meydana gelir.

$\mathrm{Bu}$ çalışmada, iki bantlı spektral rezonansları destekleyen $\mathrm{U}$ şekilli nano antenlerden oluşan kompakt bir metamalzeme tabanlı çip incelenmiştir. Metamalzeme tabanlı antenin spektral tepkisi hem sayısal hem de deneysel olarak araştırılmıştır. İkili rezonans davranışın fiziksel kökenini anlamak için sonlu fark zaman alanı (FDTD) yöntemi ile yapıyı analiz ederek rezonans modları ve alan dağılımları elde edilmiştir. Antenlerin çevresindeki güçlendirilmiş yakın elektrik alan dağılımları matematiksel olarak incelenmiştir. Rezonans düşüşlerinin geometrik parametrelere bağımlı olarak spektral değişimi de incelenmiştir.
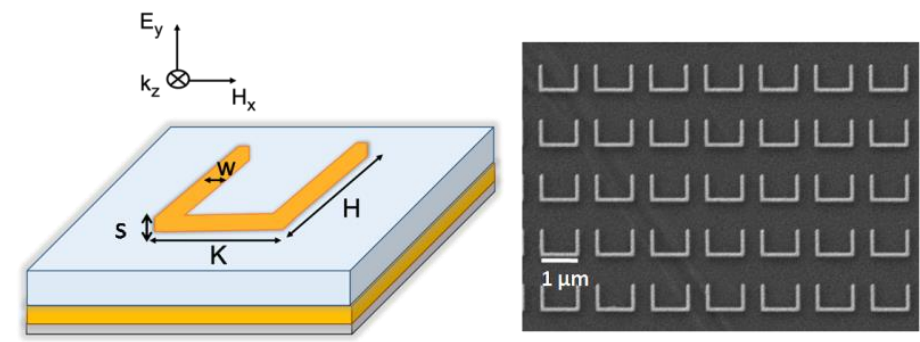

Şekil 1. Önerilen U biçimli metamalzeme anten tasarımının şematik görünümü (Sol) Geometrik parametreler dahil U biçimli metamalzemelerin üstten görünümü: K uzunluk; $H$ yükseklik; $w$ anten genişliği. Y-polarize aydınlatma kaynă̆ıda şekilde gösterilmektedir. $U$ anten kalınlığ $40 \mathrm{~nm}$ altın $(A u), 5 \mathrm{~nm}$ titanyum (Ti); alttaş kalınlıklarl $200 \mathrm{~nm} A u$ ve $140 \mathrm{~nm}$ kalınlı̆̆ında $\mathrm{SiO}_{2}$ tabakalarıdan oluşmaktadır. (Să̆) Üretilmiş $U$ şekilli antenlerin SEM görüntüsü.

\section{Materyal ve Metot}

\subsection{Sayısal Analiz}

Önerilen iki rezonanslı U-şekilli metamalzeme tabanlı anten tasarımının şematik görünümü Şekil 1' de gösterilmektedir. Alttaş olarak Silisyum, hemen üzerine $200 \mathrm{~nm}$ kalınlıkta $\mathrm{Au}$, yalıtkan için $140 \mathrm{~nm} \mathrm{SiO}_{2}$ ve antenler (U yapı) için $40 \mathrm{~nm}$ kalınlıkta $\mathrm{Au}$ kullanılmıştır. Bu şekilde, $\mathrm{K}$ yapının uzunluğunu, $\mathrm{H}$ yüksekliğini, w anten genişliğini belirtmektedir. Önerilen antenin spektral davranışı sayısal ve deneysel olarak araştırılmıştır. Sayısal analiz için, U-şekilli nano-antenler FDTD yöntemi ile modellenmiştir ve materyal parametreleri (Ti ve Au' nun dielektrik sabitleri) Palik referansından alınmıştır (Palik, 1985). İki ayrı elemandan oluşan birim hücrede, x ve y eksenleri boyunca periyodik sınır koşulları ve 1şık kaynağının yönü $\mathrm{z}$ doğrultusunda seçilip yine bu doğrultuda mükemmel uyumlu katmanlar sınır şartı olarak kullanılmıştır.

Şekil 2' de hesaplanan yansıma spektrumları, önerilen nanoantenin orta kızılötesi dalga boylarında iki adet rezonansı $\left(\lambda_{1}\right.$ ve $\lambda_{2}$ ) olduğunu göstermektedir. Nano-antenlerin fiziksel özellikleri değiştirilerek rezonans tepeleri kontrollü bir şekilde ayarlanabilir. U-şekilli MS' nin spektral davranışını kontrol etmek için, spektrumların $\mathrm{K}, \mathrm{H}, \mathrm{s}$ ve $\mathrm{w}$ gibi geometrik parametrelere bağımlılı̆̆ 

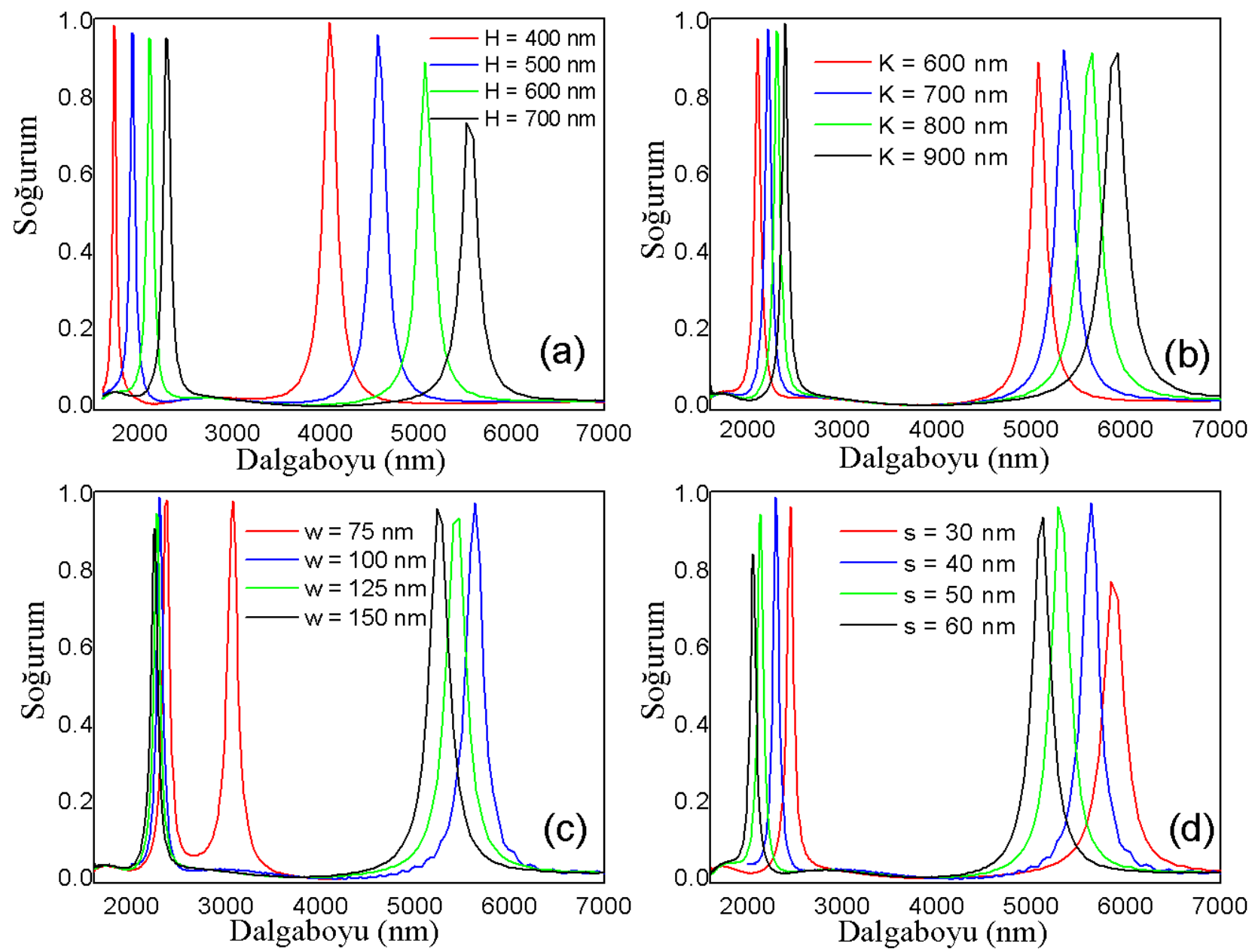

Şekil 2. Önerilen U-şekilli metamalzeme antenin FDTD yöntemi ile hesaplanan yansıma spektrumlart. Ardışık iki tepe sirasiyla $\lambda_{1}$ ve $\lambda_{2}$ dalga boylarındaki rezonanslara karşıllı gelmektedir. (a) H'nin değişen değerlerine karşıllk gelen parametreler $K=600 \mathrm{~nm}, \quad s$ $=40 \mathrm{~nm}, w=100 \mathrm{~nm}^{\prime}$ dir. (b) K' nin değiş̧en değerlerine karşıllk gelen parametreler $H=600 \mathrm{~nm}, \mathrm{~s}=40 \mathrm{~nm}, w=100 \mathrm{~nm}^{\prime}$ dir. (c) $w^{\prime}$ nin değisşen değerlerine karşıllk gelen parametreler $H=600 \mathrm{~nm}, K=600 \mathrm{~nm}, s=40 \mathrm{~nm}$ ' dir. (d) s' nin değisşen değerlerine karşıllık gelen parametreler $H=600 \mathrm{~nm}, \quad K=600 \mathrm{~nm}, w=40 \mathrm{~nm}^{\prime}$ dir. Periyot herbir veri seti için 1400nm'dir.

Antenin paralel kollarının uzunluğunun $(\mathrm{H})$ artması iki modun bağımsız olarak uyarılmasına neden olur, böylece bireysel olarak her iki yansıma spektrumu istenilen dalgaboyuna ayarlanabilir. H uzunluğunun $400 \mathrm{~nm}$ ' den $700 \mathrm{~nm}$ ' ye kadar artırılması Şekil 2(a)' da gösterildiği gibi $\lambda_{1}$ 'deki rezonans düşüşünde kayda değer bir degişime neden olmazken $\lambda_{2}$ 'deki rezonans düşüşü kuvvetli şekilde azalmaktadır. Benzer șekilde Şekil 2(b)' de U antenin taban uzunluğu K' nin $600 \mathrm{~nm}$ 'den 900 nm'ye artırılması da $\lambda_{1}$ 'deki rezonans düşüşünde kayda değer bir degişime neden olmazken $\lambda_{2}$ ' de küçük rezonans düşüşüne neden olmaktadır. Şekil 2 (a) 'da gösterilen spektrumun $\mathrm{H}$ parametresine bağlı değişimi, her iki modda da artan $\mathrm{H}$ uzunluğu ile kırmızıya doğru kuvvetli bir kayma olduğunu göstermektedir. $\mathrm{Bu}$ durum, Şekil 3' de sunulan alan modellerinin analiz edilmesiyle anlaşılabilir. $U$ anten kollarının üst-iç ve alt-dirsek köşelerinde yoğunlaşmış alan dağılımı $\lambda_{1}$ ' de ki rezonans düşüşünden sorumlu iken, $U$ anten kollarının üstü ve dış-yan duvarlarındaki güçlendirilmiş alan $\lambda_{2}$ ' deki rezonanstan düşüşünden sorumludur. Dolayısıyla bu iki alan birbiri ile etkileşmediğinden $\lambda_{1}$ ve $\lambda_{2}$ rezonansları statik olarak istenilen değere ayarlanabilir. Sonuç olarak, hesaplanan ve ölçülen yansıma spektrumlarından, önerilen metamalzeme antenin her iki rezonans modu için güçlü düşüşlere sahip olduğu görülmektedir. Bu geometri için, anten genişliği w kontrol e-ISSN:2148-2683 parametresi değiştirilerek yansıma spektrumunun değişimi Şekil 2 (c)' de gösterilmiştir. Anten genişliğinin $75,100,125$ ve 150 $\mathrm{nm}$ olduğu değerlerde $\lambda_{1}$ de neredeyse hiç değişim gözlenmezken $\lambda_{2}$ 'deki rezonans düşüşleri artan $w$ değeri ile kısa dalgaboylarına kaymaktadır. Şekil 2(c)' de $w^{\prime}$ nun artması rezonans dalga boylarını hafifçe değiştirirken, $H$ ve $K^{\prime}$ yı arttırmak yansıma spektrumunda güçlü bir kırmızıya kaymaya neden olur. Şekil 2(d)' de farklı rezonatör kalınlıklarının rezons düşüşlerine etkisi gösterilmektedir. Rezonatör kalınlığı gelen ışığın soğurulmasında dogrudan etkili olduğu için, en güçlü etkileşim rezonatörün kalınlığının $40 \mathrm{~nm}$ olduğu değerde gerçekleşmektedir. Önermiş olduğumuz $U$ anten yap1 orta-IR frekans aralığında çalışmasına rağmen, kompakt yapının geometrisi ölçeklendirilerek, rezonans konumları orta-IR' den görünür veya $\mathrm{THz}$ dalga boylarına kadar geniş bir aralıkta ayarlanabilir.

\subsection{Alan Dağılımları}

U-şekilli nano-antenlerin desteklediği iki spektral yanıtın fiziksel kökeni sayısal olarak FDTD yöntemi kullanılarak incelenmiştir. Şekil 2' de gösterilen $\lambda_{1}$ ve $\lambda_{2}$ rezonans düşüşlerine karşıllık gelen metal katman içindeki elektrik alan şiddetleri Şekil 3' de gösterilmiştir. Şekil 3' de gösterildiği gibi, her bir rezonans 
modu kompakt U yapısının bütün kısımlarının ortak (çiftlenimli) etkisinden kaynaklanmaktadır. Bu şekillerden birinci ve ikinci U-şekilli antenlerin esas modları olarak $\lambda_{1}$ ve $\lambda_{2}$ 'ye karşılık gelirken üçüncüsü toplam $\left(\lambda_{1}\right.$ ve $\left.\lambda_{2}\right)$ alan dağılımını göstermektedir. $U$ şeklindeki antenin üst kısmında içe dönük ucu, taban-dış köşeler $\lambda_{1}$ 'e karşılık gelen resonansı destekleyen güçlü elektrik alana sahiptir. Diğer yandan, U-antenin $\lambda_{2}$ 'ye karşılık gelen ikinci modu, $U$ antenin yan-dış kenarları ile üst-uç kısımlarında bulunmaktadır. $\mathrm{Bu}$ nedenle, kompakt yapının birinci ve ikinci modları, nano antenlerin bağlı (çiftlenmiş) modlarıdır.

Şekil 3 (a) ve 3 (b) 'de görüldüğü gibi birinci ve ikinci modlar için elektrik alan güçlendirilmesi 400 kattan daha büyük olduğundan Raman, floresans ve kızılötesi spektroskopide kullanılabilir.
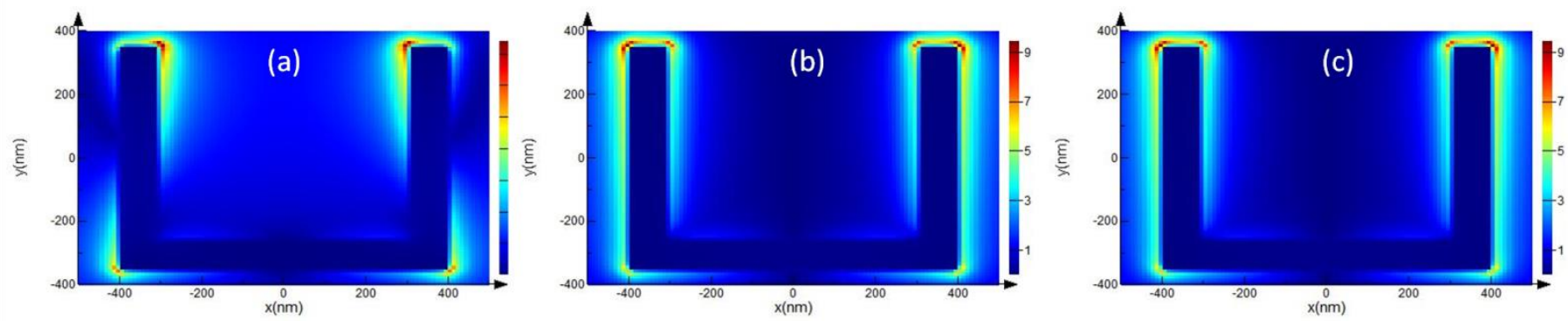

Şekil 3. U-şekilli nano-antenlerin alan dăgllımlarl. Geometrik parametreler $H=600 \mathrm{~nm}, K=600 \mathrm{~nm}, \mathrm{w}=100 \mathrm{~nm}$ ve s=40 nm alınmıştır. Sol ve ortadaki şekillerde temel modları $\lambda_{1}$ ve $\lambda_{2}$ 'ye karşılık gelen U antenlerin alan dağllımları ve en sağda ise bunların toplam alan dă̆llımı gösterilmektedir.

\subsection{Fabrikasyon Süreci}

Üretim süreci Şekil 4' de şematik olarak özetlenmiştir. İlk olarak, $200 \mathrm{~nm}$ kalınlığındaki altın tabaka elektron buharlaştırma yöntemi ile Si alttaş üzerine kaplanmıştır. Daha sonra Şekil 4 (c)' de gösterildiği gibi $140 \mathrm{~nm}$ kalınlığındaki $\mathrm{SiO}_{2}$ dielektrik tabakası termal buharlaştırma yöntemi ile altın tabaka üzerine kaplanmıştır. Şekil 4 (d)' de gösterildiği gibi elektron demet litografisi (EDL) için, pozitif ton dirençli polimetilmetakrilat (PMMA) döndürmeli kaplama yöntemi ile kaplanmıştır. Yüksek kaliteli nano yapılar elde etmek için EDL kullanılarak Şekil 4(e)' de gösterildiği gibi U şeklindeki nano-antenler desenlenmiştir. Desenleme işleminde elektron demetine maruz kalan

\section{(a) $\mathrm{Si}$ alttaș}
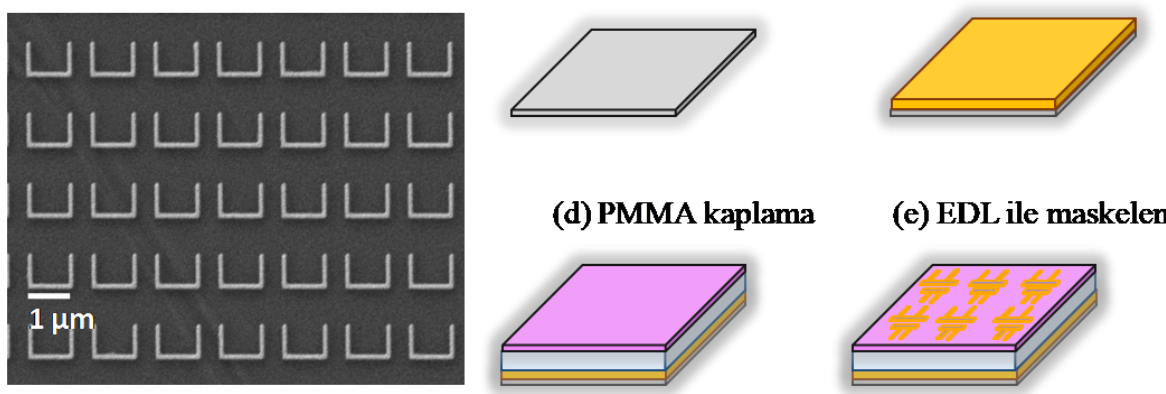

(d) PMMA kaplama

(e) EDL ile maskeleme
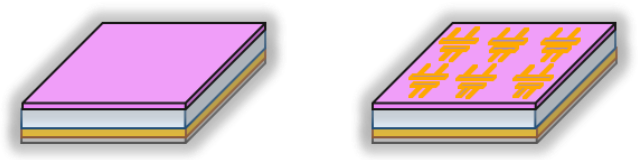

kısımlardaki PMMA moleküllerinin yapısı bozulduğu için çip metil izobütil keton (MIBK; methylisobutylketone)/ IPA/saf su içerisine daldırılarak bozulan bu kısımlar yüzeyden kaldırılır. Böylece yüzeye yapılacak olan U-şekilli antenlerin oluşturulacağ 1 kısımlar $\mathrm{SiO}_{2}$ diğer kısımlar ise PMMA olarak kalır. Üretimin son aşamasında $40 \mathrm{~nm}$ kalınlığında $\mathrm{Au}$ film çip yüzeyine kaplanır ve U-şekilli antenleri meydana çıkartmak için çip asetona batırılarak yıkanır. $\mathrm{Bu}$ aşamada $\mathrm{SiO}_{2}$ üzerine $\mathrm{Au}$ fillm yapışarak antenler oluşturulurken, PMMA üzerine kaplanan $\mathrm{Au}$ asetonla yıkama işleminde yüzeyden sökülerek atılır. SEM görüntüsünde, üretimi tamamlanmış antenlerin belirgin şekilde üretildiği ve $U$ antenlerin geniş çip yüzeyinde tek tip olduğu açıkça görülmektedir.

(b) Metal kaplama

(c) Dielektrik kaplama

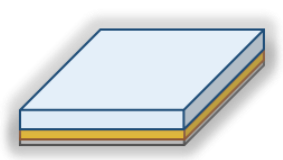

(f) Maske kaldırma ve metal kaplama

Şekil 4. Üretim şeması ve U-şekilli nano-antenlerin SEM görüntüleri. (a) Si alttaş, aseton, IPA ve DI su ile yıkanıp üretime hazır hale getirilmiştir. (b) $5 \mathrm{~nm}$ kalınlı̆̆ındaki Ti katmanından sonra $200 \mathrm{~nm}$ kalınlı̆̆ında Au film elektron buharlaştırma yöntemi ile Si Alttaş üzerine kaplanmıştır. (c) $140 \mathrm{~nm}$ kalınlı̆̆ındaki $\mathrm{SiO}_{2}$ filmi termal buharlaştırma yöntemi ile kaplanmıştır. (d) Döndürmeli kaplama yöntemi ile $\mathrm{Si}+\mathrm{Au}+\mathrm{SiO}_{2}$ üzerine PMMA kaplanarak EDL için çip hazır hale getirilmiştir. (e) U şekilli nano antenler EDL yöntemiyle PMMA üzerine desenlenmiştir. (f) EDL ile maskeleme işlemi tamamlandıktan sonra $2 \mathrm{~nm}$ Ti/ $40 \mathrm{~nm}$ Au filmi çip üzerine kaplanarak U şekilli nano-antenler ortaya çıkarılmıştır.

Üretilmiş U şekilli plazmonik nanoantenlerin taramalı elektron mikroskobu (SEM) görüntüsü Şekil 4' te gösterilmiştir. $\mathrm{Bu}$ yapılar Fourier dönüşümlü kızılötesi (FTIR) spektroskopi ile optik olarak karakterize edilmiştir. Deneysel kurulumumuz, $\mathrm{KBr}$ demet bölücü ile entegre edilmiş Bruker FTIR spektrometresine bağlı bir IR mikroskobundan oluşur. Şekil 1' de gösterilen ve anten yüzeyine normal olarak gelen elektromanyetik radyasyon, rezonatörler (antenler) üzerindeki yüzey plazmon modlarını verimli bir şekilde uyarmaktadır. $\mathrm{E}_{\mathrm{y}}$ polarize 1 şı için (E-alanının U şeklindeki antenin her iki koluna paralel olduğu durumda) yapı, iki farklı rezonans sağlar. $E_{x}$ polarizasyonu için, yalnızca çift bantlı bir rezonans davranışı vardır (veriler 
gösterilmemiştir). Yansıyan kızılötesi sinyal, bir Cassagrian yansıma optiği $(\mathrm{NA}=0.4)$ tarafından toplanır ve bir sıvı azot $\left(\mathrm{N}_{2}\right)$ soğutmalı cıva kadmiyum tellürür (MCT) detektörüne bağlanır. Yansıma verileri, altın bir aynadan alınan optik sinyal ile normalize edilerek istenmeyen elektronik ve arka plan gürültüsü elimine edilmiştir.

\section{Araştırma Sonuçları ve Tartışma}

U şekilli metamalzeme tabanlı MS sisteminin rezonans dalgaboyu ve düşüşlerinin geometrik parametre bağımlılığı hem teorik hem de deneysel olarak incelenmiştir.

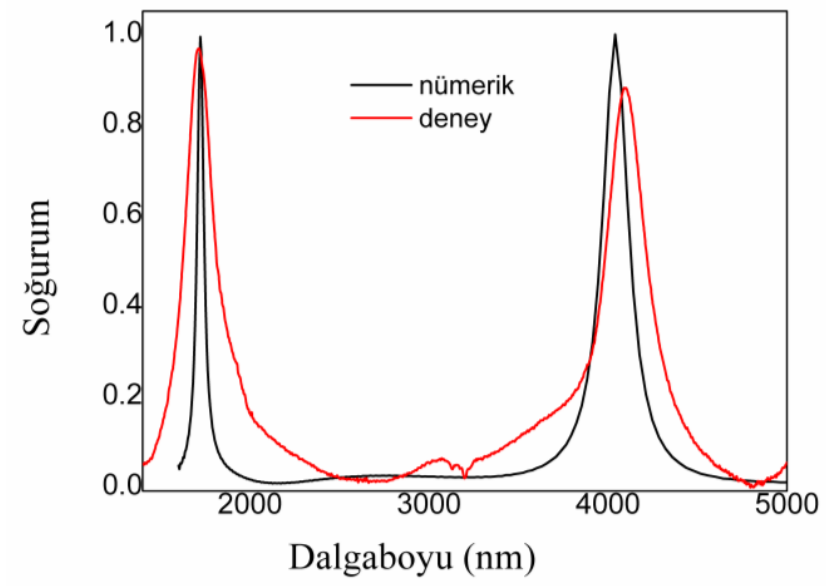

Şekil 5. U-şekilli nano-antenlerin ölçülmüsş spektrumu. Üretim ve simulasyon için kullanılan parametreler $K=600 \mathrm{~nm}, H=400$ $\mathrm{nm}, w=100 \mathrm{~nm}, \mathrm{~s}=40 \mathrm{~nm}$ ve periyot $1400 \mathrm{~nm}$ 'dir.

Deney ve simülasyon ile elde edilen sonuçların oldukça iyi uyum içinde olduğu görülmektedir. Rezonans frekansındaki küçük farklılık fabrikasyon sürecinde oluşan muhtemel hatalardan kaynaklanmaktadır. Ayrica deneysel spektrumun bant-genişliği teorik hesaplara göre daha büyük olmasının nedeni U şekilli nano-antenlerin altın yüzeyinin nispeten pürüzlü olması gelen 1şı̆̆ı saçmasından kaynaklanmaktadır.

\section{Sonuç}

Bu çalışmada kompakt U şeklindeki nano antenlere dayanan iki rezonanslı metamalzeme tabanlı mükemmel soğurucu sunulmuştur. Benzetimi gerçekleştirilen MS' nin soğurum tepkisi nümerik olarak (\% 99,4 - \% 98,5), deneysel olarak (\% 95 - \% 85) gösterilmiştir. Rezonans modları, antenlerin yapısal parametreleri değiştirilerek kolayca istenilen frekanslara ayarlanabilmektedir. Orta IR bölgesinden görünür dalga boylarına veya $\mathrm{THz}$ bölgeye kadar ayarlanabilir rezonanslara sahip bu tür metamalzemeler, aktif filtreler, optik modülatörler ve biyo-sensörler dahil olmak üzere çip tabanlı frekans seçici optik cihazlar için geniş kapsamlı sonuçlara sahip olabilir.

\section{Teşekkür}

$\mathrm{Bu}$ çalışmanın yürütülmesinde destek veren Karamanoğlu Mehmetbey ve Boston Üniversitesi'ne teşekkür ederiz.

\section{Kaynakça}

A. Degiron, H. N. (2004). Optical transmission properties of a single subwavelength aperture in a real metal. Optics Communications , 61-66.

Ahmet Ali Yanik, X. W. (2008). Extraordinary midinfrared transmission of rectangular coaxial nanoaperture arrays. Appl. Phys. Lett. , 93, 081104.

Alexander Belushkin, F. Y. (2018). Nanoparticle-Enhanced Plasmonic Biosensor for Digital Biomarker Detection in a Microarray. ACS Nano , 12 (5), 4453-4461.

Arif E. Cetin, S. K. (2016). Quantification of Multiple Molecular Fingerprints by Dual-Resonant Perfect Absorber. $A d v$. Optical Mater. , 4, 1274-1280.

Biagioni, T. T. (2019). Semiconductor infrared plasmonics. Nanophotonics , 8 (6), 949-990.

Bowen Li, S. Z. (2017). Single-Nanoparticle Plasmonic Electrooptic Modulator Based on MoS2 Monolayers. ACS Nano, 11 (10), 9720-9727.

C. M. Soukoulis, S. L. (2007). "Physics. Negative refractive index at optical wavelengths,. Science , 315 (5808), 47-49.

Cameron Gilroy, S. H. (2019). Roles of Superchirality and Interference in Chiral Plasmonic Biodetection. J. Phys. Chem. C, 123 (24), 15195-15203.

Deepak Sood, C. C. (2017). A polarization insensitive compact ultrathin wide-angle penta-band metamaterial absorber. Journal of Electromagnetic Waves and Applications , 31 (4), 394-404.

Grisha Spektor, A. D. (2015). Metafocusing by a Metaspiral Plasmonic Lens. Nano Lett. , 15 (9), 5739-5743.

Khwanchai Tantiwanichapan, X. W. (2017). Graphene terahertz plasmons: A combined transmission spectroscopy and Raman microscopy study. ACS Photonics , 4 (8), 2011-2017.

Luc Duempelmann, A. L.-D. (2016). Four-Fold Color Filter Based on Plasmonic Phase Retarder. ACS Photonics , 3 (2), 190-196.

N. I. Landy, S. S. (2008). Perfect metamaterial absorber. Phys. Rev. Lett. , 100, 207402.

Palik, E. D. (1985). Handbook of Optical Constants of Solids. Orlando, FL: Academic.

Rana Sadaf Anwar, H. N. (2018). Recent advancements in surface plasmon polaritons-plasmonics in subwavelength structures in microwave and terahertz regimes. Digital Communications and Networks , 4 (4), 244-257.

Seon-Young Rhim, G. L.-K. (2020). Using Active Surface Plasmons in a Multibit Optical Storage Device to Emulate Long-Term Synaptic Plasticity. Physica status solidi , 217 (20), 2000354.

Ting Xie, Z. C. (2017). A wide-angle and polarization insensitive infrared broad band metamaterial absorber. Optics Communications , 383, 81-86.

Tsai, M.-W. \&.-H.-Y.-c.-2. (2006). Bragg scattering of surface plasmon polaritons on extraordinary transmission through silver periodic perforated hole arrays. Applied Physics Letters. , 88, 213112.

Wang Xin, Z. B. (2017). Design, Fabrication, and Characterization of a Flexible Dual-Band Metamaterial Absorber. IEEE Photonics Journal , 9 (4), 1-12.

Yakov Galutin, E. F. (2017). Invisibility Cloaking Scheme by Evanescent Fields Distortion on Composite Plasmonic Waveguides with Si Nano-Spacer. Scientific Reports, 12076. 
Yasa Ekşioğlu, A. E. (2018). Multi-band plasmonic platform utilizing UT-shaped graphene antenna arrays. Plasmonics , 13 (3), 1081-1088.

Zhi Hao Jiang, S. Y. (2011). Conformal Dual-Band NearPerfectly Absorbing Mid-Infrared Metamaterial Coating. ACS Nano , 5 (6), 4641-4647. 